Canadian Journal of Applied Linguistics

Revue canadienne de linguistique appliquée

\title{
Does Prewriting Planning Positively Impact English L2 Students' Integrated Writing Performance?
}

\section{Pakize Uludag, Kim McDonough et Caroline Payant}

Volume 24, numéro 3, automne 2021

URI : https://id.erudit.org/iderudit/1084815ar

DOI : https://doi.org/10.37213/cjal.2021.31313

\section{Aller au sommaire du numéro}

\section{Éditeur(s)}

University of New Brunswick

\section{ISSN}

1920-1818 (numérique)

Découvrir la revue

Citer cet article

Uludag, P., McDonough, K. \& Payant, C. (2021). Does Prewriting Planning Positively Impact English L2 Students' Integrated Writing Performance? Canadian Journal of Applied Linguistics / Revue canadienne de linguistique appliquée, 24(3), 166-185. https://doi.org/10.37213/cjal.2021.31313

\section{Résumé de l'article}

La recherche sur la planification en écriture a surtout exploré les tâches d'écriture indépendantes, et peu d'études ont examiné la planification lors de la pré-écriture et la performance avec des tâches d'écriture intégrée. Ainsi, cette étude a comparé la performance de scripteurs d'anglais L2 (N=111) lors d'une tâche d'écriture intégrée issue de l'évaluation de la Canadian Academic English Language (CAEL) sous trois conditions de planification: une planification exigée avec et sans contrainte de temps et une planification avec un temps suggéré. Les rédactions ont été évaluées selon les bandes d'écriture du CAEL. Les effets des trois conditions, le temps d'écriture et les notes ont été analysés en utilisant le test MANOVA. Les entrevues des étudiants ont été analysées à l'aide d'une analyse de contenu thématique. Les résultats ont indiqué que la seule variable affectée par la condition de planification était le temps de planification : la planification exigée sans contrainte de temps. Les perceptions des étudiants sont discutées et des retombées pour l'enseignement et l'évaluation de l'écriture intégrée en L2 sont présentées.
Copyright @ Pakize Uludag, Kim McDonough, Caroline Payant, 2021

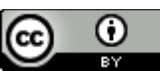

Ce document est protégé par la loi sur le droit d'auteur. L'utilisation des services d'Érudit (y compris la reproduction) est assujettie à sa politique d'utilisation que vous pouvez consulter en ligne.

https://apropos.erudit.org/fr/usagers/politique-dutilisation/ 


\title{
Does Prewriting Planning Positively Impact English L2 Students' Integrated Writing Performance?
}

\author{
Pakize Uludag \\ Concordia University \\ Kim McDonough \\ Concordia University \\ Caroline Payant \\ Université du Québec à Montréal
}

\begin{abstract}
This study compared English L2 writers' $(N=111)$ performance on an integrated writing task from the Canadian Academic English Language (CAEL) Assessment under three prewriting planning conditions: required self-timed planning required fixed time planning, and suggested (i.e., optional) planning. The participants' integrated essays were scored according to the CAEL writing bands by raters at Paragon Testing Inc. The effect of planning condition on the participants' planning time, writing time, and integrated writing scores were analyzed using MANOVA. The student interviews were analyzed using thematic content analysis. The results indicated that planning time was the only variable impacted by planning condition, with students in the required self-timed planning condition taking more time to plan before beginning to write. Students' perceptions about prewriting planning are discussed in terms of implications for the teaching and assessment of L2 integrated writing.
\end{abstract}

\section{Resumé}

La recherche sur la planification en écriture a surtout exploré les tâches d'écriture indépendantes, et peu d'études ont examiné la planification lors de la pré-écriture et la performance avec des tâches d'écriture intégrée. Ainsi, cette étude a comparé la performance de scripteurs d'anglais L2 ( $\mathrm{N}=111)$ lors d'une tâche d'écriture intégrée issue de l'évaluation de la Canadian Academic English Language (CAEL) sous trois conditions de planification: une planification exigée avec et sans contrainte de temps et une planification avec un temps suggéré. Les rédactions ont été évaluées selon les bandes d'écriture du CAEL. Les effets des trois conditions, le temps d'écriture et les notes ont été analysés en utilisant le test MANOVA. Les entrevues des étudiants ont été analysées à l'aide d'une analyse de contenu thématique. Les résultats ont indiqué que la seule variable affectée par la condition de planification était le temps de planification : la planification exigée sans contrainte de temps. Les perceptions des étudiants sont discutées et des retombées pour l'enseignement et l'évaluation de l'écriture intégrée en L2 sont présentées. 


\section{Does Prewriting Planning Positively Impact English L2 Students' Integrated Writing Performance?}

\section{Introduction}

Writing research with first (L1) and second (L2) language writers has shown that planning can unfold prior to composing the essay (i.e., prewriting planning) and while composing the essay (i.e., online planning), during which writers allocate time for and focus their attentional resources on idea generation, organization and goal setting (Johnson et al., 2012; Rahimpour \& Safarie, 2011). Building on the cognitive models used in L1 writing studies, L2 writing researchers have reported mixed findings as to whether prewriting planning impacts textual quality in terms of fluency (syllables or words per minute), accuracy (error-free structures), and complexity (number of different forms) (Ellis \& Yuan, 2004; Johnson, 2017; Johnson et al., 2012; Ong \& Zhang, 2010). In addition, L2 prewriting planning research to date has largely focused on analyses of textual quality in independent writing tasks such as narratives (e.g., Ellis \& Yuan, 2004) and opinion essays (e.g., Ong \& Zhang, 2010). Considering the role of cognitive factors in L2 language production, questions have been raised about whether prewriting planning impacts L2 writers' integrated writing task performance by mitigating pressure on writing performance. To address this gap, the current study compares how different prewriting planning conditions impact English L2 writers' performance on an integrated writing task.

In L2 writing classrooms, instructors emphasize a dynamic writing process that involves stages of prewriting planning, composing, revising, and rewriting rather than merely focus on the final product (Hyland, 2019; Nunan, 2001). During the prewriting stage, writers generate ideas through brainstorming and structure their ideas, which helps them organize their thought processes (Badger \& White, 2000; Lan et al., 2015). Apart from generating and organizing ideas, L2 writers may use prewriting planning time to set writing goals and focus on linguistic and organizational aspects of their texts (Chamot, 2005). Therefore, allocating more time for prewriting planning may contribute to the quality of the L2 students' written texts based on a process-based approach.

\section{L1 Writing Model: Supporting a Process-based Approach to Writing Pedagogy}

To explore prewriting planning as one of several sub-processes involved in composing, writing researchers have drawn on existing theories and models. While there is no universally accepted theory of writing (Grabe, 2001), L2 writing researchers have largely adopted Robinson's (2001, 2005) cognition hypothesis, Skehan's (1998) limited attentional capacity model, and Kellogg's (1996) model of working memory to discuss the impact of planning time and task conditions on the complexity, accuracy, and fluency of written texts. These theories build on similar constructs such as attentional/working memory resources and cognitive complexity, to account for the three sub-processes involved in prewriting planning (i.e., idea generation, organization, and goal setting).

The limited attentional capacity model (Skehan, 1998; Skehan \& Foster, 2001) states that learners' attentional resources are limited. Increasing task complexity will require more attentional resources from learners and attending to one task dimension (e.g., accuracy) will negatively affect another task dimension (e.g., fluency). In contrast, 
Robinson's $(2001,2005)$ cognition hypothesis states that increasing cognitive demands of tasks will not impede learners' language production as long as their attention is not directed to the same memory resource (i.e., resource-dispersing factors in Robinson's terminology). Johnson's (2017) meta-analysis of previous L2 writing research on cognitive task complexity has shown that writers devote their attentional resources to the formulation and monitoring systems of the writing processes, which place the greatest demands on working memory (Kellogg, 1996). Since manipulating planning time may relieve the pressure on working memory capacity, we adopt Kellogg's model of writing processes to explain how different planning conditions relate to different components of working memory.

Kellogg's model captures three major systems underlying written production: formulation, execution, and monitoring. Each of these systems interact and are mediated by an individual's working memory capacity. The first system, formulation, includes two processes: planning and translating where writers set goals and activate their ideas and linguistic systems (lexical and syntactic frames) in relation to their writing goals, respectively. The second system, execution, also includes two processes (programming and execution) that writers require to perform the writing task, namely, the actual production of the sentence. The third component, monitoring, comprises reading and editing activities. The processes involved in editing can be oriented towards local (e.g., language) and global (e.g., organization) aspects of the text. According to Kellogg, these three primary systems (formulation, execution, and monitoring) can be activated simultaneously and compete for a writer's limited attentional demands while composing a text. Thus, allocating time for prewriting planning might reduce the demands placed on one of the working memory components and writers can divert much of their attentional capacity to activating lexical and syntactic frames. This process has been shown to lead to an increase in writing fluency (Graham \& Perin, 2007; Page-Voth \& Graham, 1999; Troia \& Graham, 2002) and grammatical complexity (Kellogg, 1987, 1988) in L1 writers.

\section{Prewriting Planning and L2 Written Performance}

The potential benefits of prewriting planning have also been investigated by L2 writing researchers who examined whether the amount or type of planning impacts the quality of student writing. In a comparative study about prewriting planning conditions, Ong and Zhang (2010) provided Chinese EFL learners with varying amounts of time before writing argumentative essays across three conditions: pre-writing (30 minutes to plan and write), pre-task (10 minutes to plan, 20 minutes to write) and extended pre-task (10 minutes to plan and 20 minutes to write). Their results showed that free writing condition led to greater fluency (the mean number of words per minute) and lexical complexity (i.e., word types squared divided by the total number of words). The researchers speculated that because writers in pre-task and extended pre-task conditions were aware of the constraints on composing time, these conditions were possibly more cognitively demanding than free writing condition. In a follow-up study, Ong (2014) explored whether the amount of prewriting planning time was related to Chinese EFL students' metacognitive processes (e.g., generating new ideas, elaborating new ideas) both during prewriting planning and online planning argumentative essays. They found that during the planning stage, planning time conditions did not have any effects on students' 
metacognitive processes. However, during the writing stage, writers in pre-task (10 minutes planning) and extended pre-task conditions (20 minutes planning) reported thinking about language aspects of the task more frequently than the writers in the control group. Using a similar research design, Johnson et al. (2012) investigated whether EFL learners in Peru benefited from different prewriting conditions (i.e., idea generation, organization, and goal setting) holding planning and writing time constant for all writers. Students' texts were assessed in terms of fluency, lexical diversity, and grammatical complexity measures. There was no effect for prewriting planning on the students' lexical complexity or grammatical complexity, but there was a slight positive effect on fluency, which was measured as average sentence length.

Although studies have reported positive findings for prewriting planning and complexity and fluency measures, findings for accuracy have been conflicting. For example, Ellis and Yuan (2004), compared whether the 10-minute prewriting planning period online planning and no planning impacted EFL learners' written narratives. They found that allocating 10 minutes of prewriting planning time helped EFL learners produce texts that were more fluent and syntactically complex, but it had no effect on accuracy. Using a descriptive writing task elicited through a pictorial task, Tabari (2016) compared the effects of prewriting planning ( 8 minutes), online planning, and no planning conditions on Iranian EFL writers' textual quality. In terms of fluency, students in prewriting planning condition outperformed those in online planning and no planning condition. However, there was no statistically significant impact of planning conditions on the accuracy of students' texts. Therefore, taken together, these findings provide mixed evidence in terms of the impact of prewriting planning on the linguistic features of texts produced by L2 writers.

\section{Integrated Writing Tasks}

Whereas prior studies have focused on independent writing tasks, in which students can respond to the writing prompt by drawing on personal opinions and knowledge, less is known about whether prewriting planning facilitates integrated writing task performance. In contrast to independent writing, integrated writing tasks require writers to build a coherent argument by drawing on and integrating content presented in written or aural sources (Esmaeili, 2002; Gebril \& Plakans, 2013). They also elicit more sophisticated linguistic features (Cumming, 2013; Guo et al., 2013) and organizational patterns (Plakans \& Gebril, 2017). Because L2 writers need to devote their attentional capacity to multiple pools of resources (Kellogg, 1996), they have been shown to experience some challenges associated with integrated writing tasks, which include recognizing relevant ideas in source materials (Gebril \& Plakans, 2013; Sawaki et al., 2013), synthesizing information from multiple sources (Shi, 2004; Zhang, 2013), and paraphrasing/summarising source-text ideas with lexical and syntactic modifications (Sawaki et al., 2013; Shi, 2012). To alleviate some of these challenges, high-stakes proficiency tests such as TOEFL and CAEL, advise test-takers to allocate time to plan their essays prior to writing. During the planning stage, test-takers could direct their attentional resources to idea generation, organization, and goal setting, so prewriting planning could help them the same way it might with independent writing tasks. Test-takers might also revisit source materials for accurate comprehension and selection of relevant ideas during prewriting planning, which would free up their 
attentional resources to focus on linguistic forms while composing. However, little is known about whether the amount of prewriting planning or students' behaviour during prewriting planning are related to integrated writing test performance.

To explore these issues, a recent study by Payant et al., (2019) examined whether any prewriting planning variables (amount of time, note-taking strategy type, elaborateness of notes, or required versus suggested planning) predicted writing band scores on the integrated writing task of the Canadian Academic English Language (CAEL) test which suggests that examinees use 15 minutes (out of 45) to plan. Although the regression model did not include any prewriting planning variables as significant predictors of integrated writing performance, the qualitative analysis demonstrated a link between how students use prewriting planning time and text quality. For example, students who stated that they used planning time to revise their reading comprehension notes and recall ideas from the readings received higher band scores. The null findings for all planning variables, however, raise questions about whether the benefits of prewriting planning are sufficient to justify the recommendation that writers use one-third of the total examination time for planning.

In addition, to date, relatively few prewriting planning studies have elicited L2 writers' perceptions about prewriting planning, such as what value they attribute to planning or how they use planning time. Drawing on questionnaire data, researchers have reported that L2 writers associated prewriting planning with content and rhetorical development (Ellis \& Yuan, 2004). Interview data revealed that L2 writers who scored higher on a CAEL integrated writing task devoted prewriting planning time to ensuring source-text comprehension (Payant et al., 2019). The findings from writer perception studies indicate that learners indeed value and use prewriting planning time (Silva, 1992) While these studies shed some light on L2 writers' perceptions about prewriting planning, further qualitative data are needed to reveal under what conditions L2 writers value prewriting planning,

To summarize, the provision of prewriting planning has been claimed to positively impact L2 writing performance by reducing the cognitive load associated with writing. However, existing studies have been limited to independent writing tasks that explored the impact of prewriting planning on linguistic features of student texts (e.g., complexity, accuracy, and fluency), without documenting students' actual use of the planning time. In addition, to the best of our knowledge, how students perceive prewriting planning has not been empirically investigated. Therefore, it is important to discover how L2 writers' attentional resources are directed during planning and composing phases. To further explore the impact of different prewriting planning conditions on English L2 students' integrated writing performance, this study draws upon data from a larger study (Payant et al., 2019) to address the following research questions:

1. Is there a difference between L2 students' performance on the CAEL integrated writing task in terms of planning time, composing time, and band scores?

2. What are their perceptions about prewriting planning? 


\section{Method}

\section{Participants}

The data come from a larger study about prewriting planning (Payant et al., 2019) in which 111 English L2 students (41 males, 70 females) at an English-medium Canadian University carried out a paper-based CAEL test (reading, listening, and writing) in a laboratory setting. They ranged in age from 18 to 52 , with a mean age of 22.6 years $(S D=$ 5.7). They self-reported studying English previously for a mean of 8.9 years $(\mathrm{SD}=5.1)$ and residing in Canada for 17.5 months $(S D=20.2)$. They spoke a variety of L1s including Mandarin (43), Arabic (20), French (16), Spanish (12), Farsi (4), Vietnamese (3), Haitian Creole (2), Italian (2), along with one speaker each of Bengali, Berber, Bulgarian, Japanese, Malay, Mongolian, Portuguese, Russian, and Tagalog. The students reported having previously taken a standardized proficiency test, which were either IELTS or the TOEFL iBT. Only two students reported having taken the CAEL test. Their scores ranged from 75 to 89 on the TOEFL iBT or equivalent. Although their proficiency scores were sufficient to enter their degree programs and take subject-matter courses, they were required to take an intensive English for Academic Purposes (EAP) writing course (165 minutes per week for 13 weeks) based on their performance on a university placement exam. The EAP course focused on improving reading comprehension, knowledge of academic vocabulary and grammatical structures, and academic writing skills including process-based writing strategies and source-based writing tasks. However, the data were collected at the beginning of the semester when the EAP course targeted academic vocabulary and grammatical structures. Since the students had already been admitted to degree programs, the EAP course emphasized academic writing tasks relevant for university studies as opposed to strategies for taking standardized proficiency tests.

\section{Material}

To elicit a source-based essay from the participants, a sample paper-based CAEL test provided by Paragon Testing Inc. was administered. The CAEL test is a large-scale, topic-based language assessment that measures English proficiency based on performance in reading, listening, and academic writing sections. Following the CAEL test protocol, the students completed all four sections of the test (Reading 1, Listening, Reading 2, Integrated Writing) during an individual data collection session in a laboratory setting (150-160 min). The topic was long-range weather forecasting. The first reading passage (1069 words) was an academic text while the second passage (1463 words) was a news report, both of which were followed by multiple-choice, open-ended, and cloze comprehension questions. The aural lecture (12 minutes), which occurred between the two reading passages, was followed by listening comprehension questions and graphic organizers with missing information. The writing prompt was to provide an opinion about the feasibility of reporting long-range forecasting using information from the readings and lecture to justify their opinion. As prescribed by the CAEL administration guidelines, the students received the writing prompt prior to carrying out the reading and listening sections. 


\section{Design}

The study adopted an experimental, between-group design to compare the effect of different prewriting planning conditions on English L2 students' performance on a CAEL integrated writing task. Three prewriting planning conditions were created that manipulated a) whether planning was required and b) the amount of planning time, as summarized in Table 1. Students within gender and L1 groups were randomly assigned to one of the three experimental groups.

Table 1

Planning Conditions $(N=111)$

\begin{tabular}{lccc}
\hline Phase & $\begin{array}{c}\text { Required fixed time } \\
(n=38)\end{array}$ & $\begin{array}{c}\text { Required self-timed } \\
(n=36)\end{array}$ & $\begin{array}{c}\text { Suggested planning } \\
(n=37)\end{array}$ \\
\hline Planning & $\begin{array}{c}\text { Mandatory 15 } \\
\text { minutes }\end{array}$ & $\begin{array}{c}\text { Mandatory up to 15 } \\
\text { minutes }\end{array}$ & Suggested 15 minutes \\
Writing & Maximum 30 minutes & Maximum 30 minutes & Suggested 30 minutes \\
\hline
\end{tabular}

Students assigned to the suggested planning group followed the current CAEL instructions, which suggest 15 minutes for planning and 30 minutes for writing. For this group, there was no attempt to control whether or how long the students planned prior to beginning to write their essays or how much time they used to compose. In other words, these students could choose to use the entire 45 minutes for composing, which is possible under the current CAEL testing procedure. This condition was included as the control condition because it represents the common testing practice of suggesting that students plan without specifying how long they should plan, explaining what they should do during planning, or monitoring their activities during planning time. To document how students used the entire 45-minute period, the amount of time they spent during prewriting planning and composing were video recorded.

In contrast to students in the control condition, students in the required fixed time planning condition were required to plan for 15 minutes before they could start writing their essays (maximum of 30 minutes). In other words, these students were required to follow the CAEL test suggestions of 15 minutes of planning followed by 30 minutes of writing. However, it is not possible to "force" students to continue to plan if they have nothing left to think about. Therefore, the 15 minutes of planning time was enforced by not giving the students composition paper until time was up; however, the actual amount of planning time they used was recorded by noting when students stopped planning and started doing non-task related activities such as watching videos or checking email on their phones. Finally, students in the required self-timed planning condition were also required to plan, but they were told to take as much time as they needed up to 15 minutes, after which they would have 30 minutes to compose. This condition also imposed a planning period by withholding composition paper but did not require that students use the entire 15 minutes. So, it was possible for students to stop planning after a few minutes and ask for the composition paper. The key difference between the two required planning groups was whether the amount of time for prewriting planning (15 minutes) was "required" or "suggested" with actual prewriting planning and composing times in both conditions recorded. 
Performance on the CAEL writing task was the outcome variable, which was operationalized in terms of three variables: a) the amount of prewriting planning time, b) the amount of composing time, and c) the CAEL writing band scores for their essays. The amount of planning and composing time were included in the analysis to determine the extent to which the planning conditions resulted in differences in the actual behaviour of the students, i.e. how much time they took to plan or write. Presumably, required planning may encourage students to spend time developing ideas and revisiting sources while suggested planning may give students more time to compose and revise their essays, both of which can potentially result in better task performance.

\section{Procedure}

The students scheduled individual data collection sessions (150 - 180 minutes) with the first researcher. After signing the consent forms they carried out the CAEL test following the instructions for test administration: Reading 1 (25 minutes), Listening (20 minutes), Reading 2 (30 minutes) and Writing (45 minutes). The participants were video recorded during the writing task to verify their self-reported planning and composing times. Although the participants were provided with the topic before they read and listened to the source materials per the CAEL instructions, they did not receive their writing booklets and could therefore not begin composing until the planning phase was completed. After carrying out the writing section, they completed a background questionnaire (10 minutes) and participated in a semi-structured interview (15-20 minutes) about their use of planning and writing time and their perceptions about prewriting planning. The interview consisted of open-ended questions that asked the students to self-report the amount of time they devoted for planning and writing, share their perceptions about the time allocated for each phase, and describe the activities they engaged with during prewriting and composing (see Appendix A). The interviews were audio-recorded.

\section{Data Coding and Analysis}

The students' handwritten essays were sent to Paragon Testing for scoring, which is based on writing bands that range from 10 to 90 (see Appendix B). Unlike the TOEFL test, CAEL band scores are categorical, not numeric, and thus, median/IQR were more appropriate to report. The students' self-reported planning and composing times during the interviews were checked against the video recordings to ensure accuracy. To compare the effect of planning condition on the students' integrated writing performance, a MANOVA was used to account for the three dependent variables: planning time, writing time, and CAEL writing band scores. Although MANOVAs are not widely used in L2 research (Larson-Hall, 2010), they provide information about intercorrelations among dependent variables and reduce the risk of Type 1 errors associated with the use of multiple, one-way ANOVAs (Huberty \& Morris, 1989). In terms of assumptions, the equality of covariance matrices was confirmed by running a Box's M test $(p=0.010)$. Absence of multivariate outliers was assumed as there were no participants with a Mahalanobis value greater than 16.27. As sample sizes were nearly equal across groups, Pillai's trace was reported as having the most power (Field, 2017; Stevens, 1980). Alpha was set at .05. 
The audio-recorded interviews were transcribed and verified for content accuracy by research assistants. To address the second research question about students' perceptions, the first researcher followed the qualitative content analysis procedures described by Dörnyei (2007). The entire data set was reviewed to identify initial codes during a preliminary exploration stage. Next, the data set was checked against the initial codes, which were then organized into themes using an inductive approach. Due to variation in the themes that emerged in the data from the different planning conditions, lists of themes for each condition were created. Finally, the accuracy of the themes was checked against the interviews, which led to a combination or redefinition of interrelated themes.

\section{Results}

\section{Prewriting planning conditions}

The first research question asked whether there was a difference in the effectiveness of prewriting planning conditions on English L2 students' performance on an integrated writing task, which was operationalized as their use of planning and writing time along with their CAEL writing band score. As mentioned previously, although the planning conditions either required or suggested planning time of varying lengths, the students' behaviour was recorded to determine how much time they actually spent on prewriting planning and composing. As shown in Table 2, students with required selftimed planning took longer to plan, followed by the required fixed time and suggested planning students. The required self-timed students also had the longest composing time, followed by suggested planning and required fixed time students. The median band scores showed some variation as well, with required self-timed planning students having the highest median scores.

Table 2

Group means and standard deviations for outcome variables

\begin{tabular}{ccccccc}
\hline \multicolumn{1}{c}{ Planning condition } & \multicolumn{2}{c}{ Planning time } & \multicolumn{2}{c}{ Writing time } & \multicolumn{2}{c}{ Band scores } \\
\hline & $\mathrm{M}$ & SD & M & SD & Mdn & IQR \\
\hline Required fixed time $(\mathrm{n}=38)$ & 11.8 & 3.7 & 24.6 & 5.5 & 55.5 & 12.7 \\
Required self-timed $(\mathrm{n}=36)$ & 12.1 & 2.9 & 27.2 & 3.7 & 60.3 & 13.0 \\
Suggested planning $(\mathrm{n}=37)$ & 9.5 & 4.7 & 25.8 & 5.7 & 53.3 & 13.7 \\
\hline
\end{tabular}

A MANOVA test using Pillai's trace showed that there was a significant effect for planning condition on integrated writing scores, planning time, and writing time, $F(6,106)$ $=3.40, p=.003$, partial $\eta 2=.087$. Separate univariate tests for each outcome variable revealed a significant effect for planning time, $F(2,108)=5.37, p=.006$, partial $\eta^{2}=.09$. Post-hoc comparisons with a Bonferroni correction indicated that students in both required self-timed ( $p=.01, d=.70)$ and required fixed time $(p=.025, d=.56)$ planning took significantly longer to plan than the suggested planning group. There was no difference between the required self-timed and required fixed time groups $(p=1, d=.09)$. The univariate tests indicated no significant difference for composing time, $F(2,108)=2.4, p=$ .09 , partial $\eta^{2}=.043$, or the integrated writing band scores, $F(2,108)=2.7, p=.07$, partial 
$\eta^{2}=.048$. In sum, the results indicated that planning condition had a significant impact on the students' use of planning time, but not on their composing time or CAEL writing band scores.

Although the students in the required planning conditions took longer to plan, their CAEL band scores were not significantly different from students in the suggested planning group. This pattern raises interesting questions about the relationship between the amount of time spent planning and measures of text quality. To explore this relationship further, we carried out a post-hoc correlation analysis between the amount of planning time (in minutes) and the CAEL writing band scores. The correlation coefficients for each planning condition are provided in Table 3.

\section{Table 3}

Correlation between Planning Time (in minutes) and CAEL Writing Band Scores

\begin{tabular}{lll}
\hline Planning Condition & $r$ & $p$ \\
\hline Required fixed time (Mandatory 15 minutes) & .24 & .15 \\
Required self-timed (Mandatory up to 15 minutes) & -.19 & .28 \\
Suggested planning (Suggested 15 minutes) & -.20 & .24 \\
\hline
\end{tabular}

Although none of the $r$ values reached statistical significance, the pattern of results suggests that the length of self-timed prewriting planning (required or suggested) was negatively associated with writing band scores. In other words, the longer these students planned, the lower their band scores were. The post-hoc analysis should be considered speculative, however, as the current study was not designed to rigorously explore the relationship between the amount of planning time and task performance.

\section{Perceptions about Prewriting Planning}

The second research question asked about the participants' perceptions about prewriting planning. Two major themes emerged from the data: the length of prewriting planning and planning behaviour. Because the students' perceptions about the length of prewriting planning varied based on whether planning was required or suggested, their comments are reported separately. Most students in the two required planning conditions perceived 15 minutes as an appropriate amount of time to spend planning prior to writing, as illustrated by the following comments:

P61: Yeah, 15 minutes is enough for me because when I see the title for the question for this essay I already have the plan. I just write this point by point. P49: I think yes, 15 minutes is enough. But because I just read it before

Interestingly, in terms of their actual behaviour during planning time (i.e., the amount of time they actually spent before beginning to compose), only half of these students $(53 \%)$ used the full 15 minutes. Furthermore, several students said that they would have benefited from additional time to plan, even though they had not used the full allotted time. This indicates a mismatch between their perceived and actual use of planning time. 
P11: I think 15 minutes okay for me, but I would like to have more time if possible. P35: I think the same (ideal amount of time). Maybe 20 minutes would be better.

In contrast, students in the suggested planning group, which received the current CAEL instructions that suggest 15 minutes to plan and 30 minutes to write, reported taking less time than the suggested 15 minutes. For example, P94 explained as follows: I think 5 minutes is enough for me, because it's kind of short. These students may have taken less time for prewriting planning in favour of generating ideas during the execution stage of composing as illustrated by this comment:

P79: I used only 8 minutes because I really was generating idea when I'm writing because really, I will change my idea, my idea altered when I suddenly maybe come up with some idea from somewhere else or something else.

Thus, for students who were required to engage in prewriting planning, there was a gap in their perception about their use of planning time in that they reported using the allotted 15 minutes or requesting more time, even though they spent less than 15 minutes planning. In the suggested planning group, students took less time to plan (as confirmed by the MANOVA), perhaps in part because they preferred to plan while writing. Therefore, even if the current CAEL instructions for writing recommend 15 minutes of prewriting planning, it is possible for test-takers not to follow them.

Turning to the second theme about planning behaviour, students across the planning conditions reported similar comments about what they did while planning. They primarily used the planning time to brainstorm ideas, list key points, write a thesis statement, and generate ideas for the body paragraphs, as illustrated here by P51:

During that 15 minutes first I was thinking about my thesis, so what was my position on the subject. Then I just brainstorm very quickly all my ideas, why I was for this position what I was in favour. Then I first write my first ideas, my main idea.

In addition to generating ideas, several students reported that they used planning time to revisit the sources to locate supporting examples, which provides evidence to support the role of planning in integrated writing:

P4: I really tried to make my draft really clear in my head and on the paper. And I say like /---/ reason I want to - to talk about, and then example and where I find the information if I find them in the text.

P104: Okay, so I was thinking about the article that I read but especially the lecture, the listening part, because I really retained from the lecture and yeah I based my writing on it and on some aspects I think in the second reading they talk more about the economical and social aspects.

Although they solicited content information from the sources during prewriting, the students did not report using planning time to paraphrase or linguistically modify sourcetext information. It appears that these students, regardless of whether prewriting planning 
was required or suggested, primarily used planning time to formulate ideas and revisit the source texts to locate information to support their ideas.

\section{Discussion}

The current study compared the effect of different prewriting planning conditions on L2 writers' integrated writing task performance, focusing narrowly on prewriting planning time, writing time, and CAEL writing band scores. The quantitative results indicated that planning time was the only variable affected by planning condition, with students in the required planning groups using significantly more time for prewriting planning than students in the suggested planning group. Previously, researchers have hypothesized that the benefits of prewriting planning would be more apparent in cognitively more challenging tasks that place demands on working memory resources (Kellogg, 1990), such as integrated writing tasks. These tasks do not only require students to generate ideas for responding to the prompt, but also to select, organize, and integrate information from written and oral source materials into their text (Plakans \& Gebril, 2017; Guo et al., 2013). Thus, drawing on the predictions of Kellogg's working memory model, allocating time for idea development, organization and/or goal setting during prewriting planning could relieve the components of working memory when composing integrated essays, thereby contributing to improved writing performance.

Although we found a difference in the amount of planning time, there were no differences in these students' writing time or CAEL writing band scores. In addition, there was a negative correlation between the length of self-timed prewriting planning (required or suggested) and writing band scores. It is possible that the negative relationship in the self-timed conditions (both required and suggested) was due to a tendency for more skilled writers to need less time to plan whereas weaker writers planned longer prior to beginning writing. Despite taking longer time to plan, the weaker writers still received lower writing band scores. However, when a fixed time planning period (15 minutes) is required, even the more skilled writers may take more time to plan, with the correlation coefficient becoming positive. This pattern suggests that prewriting planning may contribute to the scores only when it is required or enforced. Planning research to date has largely explored the impact of prewriting planning on complexity, accuracy, and fluency measures (e.g., Ellis \& Yuan, 2004; Johnson et al., 2012; Ong \& Zhang, 2010) as opposed to rater evaluations of text quality. In this study, we focussed on test-takers' writing scores as a measure of their integrated writing task performance. Future studies should incorporate both linguistic measures and rater evaluations to explore the relationship between planning conditions and dimensions of integrated writing performance.

With respect to manipulating task complexity, our findings conflict with those of prior research with independent writing tasks, which found that increasing prewriting planning time positively influenced L2 writers' fluency and lexical complexity (Johnson et al, 2012; Ong, 2014), or facilitated fluency but not accuracy and syntactic complexity (Ellis \& Yuan, 2004; Rahimpour \& Safarie, 2011). One possible explanation for this finding could be that planning time was manipulated for the required planning groups while writing time remained constant. Because students did not feel constraints on composing time, these conditions were not cognitively demanding for them. This could also highlight a likely explanation for the contradiction between our results and those by Ong and Zhang (2010), who reported greater fluency and lexical complexity for students in 
a free-writing condition. These converging findings motivate the need for additional studies that explore prewriting planning during integrated writing tasks.

Turning to students' perception data, the qualitative analysis revealed that students in the required planning conditions believed that 15 minutes was enough time for planning although they rarely used the entire time. They also overestimated the amount of time they spent planning. In contrast, students in the suggested planning condition needed less time for prewriting planning as they also planned while writing. Regardless of planning condition, the students reported using similar strategies during prewriting planning, including idea generation and revisiting the sources. This finding supports Kellogg's prior research drawing on think-aloud protocols, which has suggested that L2 writers tend to focus on surface-level linguistic features and perform metacognitive processes when planning before independent writing tasks (Ellis \& Yuan, 2004; Ong, 2014).

Moreover, in the absence of any explicit instructions about what to do during prewriting planning time, students in all three planning conditions consistently focused on generating content. By focusing on content during planning time, these students may have devoted greater attentional resources to focus on other aspects of their texts, such as language, while composing (Robinson, 2001, 2005). Although they did not report spending time on language during prewriting planning, it is possible that the students paraphrased or modified source-text information while composing or revising (execution and monitoring stage) as opposed to during planning time.

Our findings also indicate that prewriting planning for integrated writing tasks may be useful for helping students locate information in source texts, which they can then incorporate into their essays. Students' attentional resources are limited as shown by task complexity frameworks (Skehan \& Foster, 2001; VanPatten, 1990), and prewriting planning helps L2 writers set goals for the writing process, generate personal opinions about the topic and organize their ideas (Badger \& White, 2000; Chamot, 2005). Revisiting sources to select information reflects the process of setting goals, which makes an explicit connection to integrated writing (Payant et al., 2019). More research is needed to further explore how students use prewriting planning during integrated writing tasks to identify the processes underlying integrated writing ability.

\section{Implications}

Even though students in the required planning conditions took longer to plan but did not produce essays with higher band scores, a potential pedagogical implication is to focus on the quality rather than the length of prewriting planning. L2 writers' language proficiency levels perhaps influence the amount of time they spend on planning. Thus, it is possible that some of the skilled writers need less time to plan while less-skilled writers need longer to generate and organize ideas.

For integrated writing tasks specifically, providing instruction about how to exploit source-text information during prewriting planning may be helpful. As indicated by earlier studies, L2 writers' performance on integrated writing tasks might be influenced by source text comprehension (Esmaeili, 2002; Gebril, 2009). It is possible that some L2 writers need guidance in understanding the organizational structure of reading texts and establishing connections across information presented in multiple written and oral sources. Introducing effective reading and listening strategies and demonstrating how to make notes from 
sources may positively impact their development as academic writers promoting attention to the formulation and monitoring systems of the writing process (Kellogg, 1996).

For writers who struggle with effective paraphrasing techniques, prewriting planning may provide an opportunity for them to work with the linguistic features of source-text information before incorporating it into their essays. However, if students tend to focus on content rather than language during prewriting planning, it may be necessary to provide more explicit instructions or more structured prewriting planning tasks. For example, McDonough et al. (2018) found that collaborative prewriting discussions elicited more evaluative and reflective comments about organization when they provided a structured task handout. L2 writing instructors may need to introduce strategies for effective use of prewriting planning time to focus on selecting information from sources and organizing their ideas, which may help reduce the cognitive load associated with integrated writing tasks. For example, whereas novice writers might need strategy training for selecting relevant ideas from sources in the planning phase, more advanced writers could benefit from allocating time for making lexical and structural changes to the sourcetext language. Therefore, it is important for L2 writers to become more autonomous when deciding which cognitive processes to focus on during the composing process (Baddeley, 1996).

\section{Limitations}

In this study, students took the CAEL test in a laboratory setting, which was essentially a no-stakes context. It is not clear whether the findings would be replicated in a higher-stakes assessment setting, such as an in-class exam or standardized proficiency test. While our results do not raise doubts about the suggestion that test-takers plan before writing in high-stakes proficiency tests such as CAEL, we found no significant differences in students' task performance across different planning conditions. Future studies should seek to extend research on the relationship between prewriting planning and integrated task performance in high-stakes testing situations. The present study focussed on prewriting planning exclusively; consequently, more research is needed to discover how L2 writers engage in online planning during integrated writing tasks. Although prior research has operationalized text quality in terms of linguistic measures, we focused on CAEL writing band scores. Future research should explore the relationship between prewriting planning and writing performance as measured by rubrics from other high-stakes tests as well as the assessment tools used for in-house placement and exit exams. Finally, we also call for research about classroom-based integrated writing tasks to provide EAP instructors with additional information about how to help students acquire integrating writing skills.

Correspondence should be addressed to Pakize Uludag

Email: pakize.uludag@concordia.ca

\section{References}

Baddeley, A. (1996). Exploring the central executive. The Quarterly Journal of Experimental Psychology Section A, 49(1), 5-28. https://doi.org/10.1080/713755608 
Badger, R. \& White, B. (2000). A process genre approach to teaching. ELT Journal, 54 (2),153-160. https://doi.org/10.1093/elt/54.2.153

Chamot, A. (2005). Language learning strategy instruction: Current issues and research. Annual Review of Applied Linguistics, 25, 112-130. https://doi.org/10.1017/S0267190505000061

Cumming, A. (2013). Assessing integrated writing tasks for academic purposes: Promises and perils. Language Assessment Quarterly, 10(1), 1-8. https://doi.org/10.1080/15434303.2011.622016

Dörnyei, Z. (2007). Research methods in applied linguistics. Oxford: Oxford University Press Ellis, R. \& P. Yuan (2004). The effects of planning on fluency, complexity, and accuracy in second language narrative writing. Studies in Second Language Acquisition 26, 59-84. https://doi.org/10.1017/S0272263104261034

Esmaeili, H. (2002). Integrated reading and writing tasks and ESL students' ready and writing performance in an English language test. Canadian Modern Language Review, 58(4), 599. https://doi.org/10.3138/cmlr.58.4.599

Field, A. (2017). Discovering statistics using IBM SPSS statistics: North American Edition. Sage.

Gebril, A. (2009). Score generalizability of academic writing tasks: Does one test method fit it all? Language Testing, 26(4), 507-531. https://doi.org/10.1177/0265532209340188

Gebril A. \& Plakans, L. (2013). Towards a transparent construct of reading-to-write assessment tasks: The interface between discourse features and proficiency. Language Assessment Quarterly, 10(1), 9-27. https://doi.org/10.1080/15434303.2011.642040

Grabe, W. (2001). Notes toward a theory of second language writing. On second language Writing. In T. Silva \& P.K. Matsuda (Eds.), On second language writing (pp. 3957). Lawrance Erlbaum Associates

Graham, S. \& D. Perin (2007). A meta-analysis of writing instruction for adolescent students. Journal of Educational Psychology, 99, 445-476. https://doi.org/10.1037/0022-0663.99.3.445

Guo, L., Crossley, S. A., \& McNamara, D. S. (2013). Predicting human judgments of essay quality in both integrated and independent second language writing samples: A comparison study. Assessing Writing, 18, 218-238. https://doi.org/10.1016/j.asw.2013.05.002

Huberty, C. J., \& Morris, J. D. (1989). Multivariate analysis versus multiple univariate analyses. Psychological Bulletin, 105(2), 302. https://doi.org/10.1037/00332909.105.2.302

Hyland, K. (2019). Second language writing. Cambridge university press.

Johnson, M. D., Mercado, L., \& Acevedo, A. (2012). The effect of planning sub-processes on L2 writing fluency, grammatical complexity, and lexical complexity. Journal of Second Language Writing, 21(3), 264-282.

https://doi.org/10.1016/j.jslw.2012.05.011

Johnson, M. D. (2017). Cognitive task complexity and L2 written syntactic complexity, accuracy, lexical complexity, and fluency: A research synthesis and meta-analysis. Journal of Second Language Writing, 37, 13-3. https://doi.org/10.1016/j.jslw.2017.06.001 
Kellogg, R.T. (1987). Effects of topic knowledge on the allocation of processing time and cognitive effort to writing processes. Memory \& Cognition, 15, 256- 266. https://doi.org/10.3758/BF03197724

Kellogg, R.T. (1988). Attentional overload and writing performance: Effects of rough draft and outline strategies. Journal of Experimental Psychology: Learning, Memory \& Cognition, 14, 355- 365. https://doi.org/10.1037//0278-7393.14.2.355

Kellogg, R. T. (1990). Effectiveness of prewriting strategies as a function of task demands. The American Journal of Psychology, 327-342. https://doi.org/10.2307/1423213

Kellogg, R. T. (1996). A model of working memory in writing. In C. M. Levy \& S. Ransdell (Eds.), The science of writing: Theories, methods, individual differences, and applications (pp. 57-71). Lawrence Erlbaum Associates, Inc.

Lan, Y.-J. \& Sung, Y.-T. \& Cheng, C.-C. \& Chang, K.-E. (2015). Computer-supported cooperative prewriting for enhancing young EFL learners' writing performance. Language Learning \& Technology, 19(2), 134-155. http://dx.doi.org/10125/44421

Larson-Hall, J. (2010). Chapter 4: Changing the way we do statistics: Hypothesis testing, power, effect size, and other misunderstood issues. A guide to doing statistics research using SPSS (pp. 96-125). https://doi.org/10.4324/9780203875964

McDonough, K., De Vleeschauwer, J., \& Crawford, W. (2018). Comparing the quality of collaborative writing, collaborative prewriting, and individual texts in a Thai EFL context. System, 74, 109-120. https://doi.org/10.1016/j.system.2018.02.010

Nunan, D. (2001). Second language English teaching and learning. Foreign Language Teaching and Research Press.

Ong, J. \& Zhang, L. J. (2010). Effects of task complexity on the fluency and lexical complexity in EFL students' argumentative writing. Journal of Second Language Writing, 19, 218-233. https://doi.org/https://doi.org/10.1016/j.jslw.2012.03.005

Ong, J. (2014). How do planning time and task conditions affect metacognitive processes of L2 writers? Journal of Second Language Writing, 23, 17-30.

https://doi.org/10.1016/j.jslw.2013.10.002

Page-Voth, V.\& S.Graham (1999). Effects of goal setting and strategy use on the Writing performance and self-efficacy of students with writing and learning problems. Journal of Educational Psychology, 91, 230-240

https://doi.org/10.1037/0022-0663.91.2.230

Payant, C., McDonough, K., Uludag, P., \& Lindberg, R. (2019). Predicting integrated writing task performance: Source comprehension, prewriting planning, and individual differences. Journal of English for Academic Purposes, 40, 87-97. https://doi.org/10.1016/j.jeap.2019.06.001

Plakans, L., \& Gebril, A. (2017). Exploring the relationship of organization and connection with scores in integrated writing assessment. Assessing Writing, 31, 98-112. https://doi.org/10.1016/j.asw.2016.08.005

Rahimpour, M., \& Safarie, M. (2011). The effects of on-line and pre-task planning on descriptive writing of Iranian EFL learners. International Journal of English Linguistics, 1(2), 274. https://doi.org/doi:10.5539/ijel.v1n2p274

Robinson, P. (2001). Task complexity, task difficulty, and task production: Exploring interactions in a componential framework. Applied Linguistics, 22, $27-57$. http://doi.org/10.1093/applin/22.1.27. 
Robinson, P. (2005). Cognitive complexity and task sequencing: Studies in a componential framework for second language task design. IRAL-International Review of Applied Linguistics in Language Teaching, 43, 1-33. http://dx.doi.org/10.1515/iral.2005.43.1.1.

Sawaki, Y., Quinlan, T., \& Lee, Y. (2013). Understanding learner strengths and weaknesses: Assessing performance on an integrated writing task. Language Assessment Quarterly, 10(1),73-95. https://doi.org/10.1080/15434303.2011.633305

Shi, L. (2004). Textual borrowing in second-language writing. Written communication, 21(2), 171-200. https://doi.org/10.1177/0741088303262846

Shi, L. (2012). Rewriting and paraphrasing source texts in second language writing. Journal of Second Language Writing, 21, 134-148. https://doi.org/10.1016/j.jslw.2012.03.003.

Silva, T. (1992). L1 vs L2 writing; ESL graduate students' perceptions. TESL Canada journal, 27-47. https://doi.org/10.18806/tesl.v10i1.610

Skehan, P. (1998). A cognitive approach to language learning. Oxford University Press.

Skehan, P., \& Foster, P. (2001). Cognition and tasks. In P. Robinson (Ed.). Cognition and second language instruction (pp. 183-205). Cambridge University Press.

Stevens, J. P. (1980). Power of the multivariate analysis of variance tests. Psychological Bulletin, 88(3),728. https://doi.org/10.1037/0033-2909.88.3.728

Tabari, M. A. (2016). The effects of planning time on complexity, accuracy, fluency, and lexical variety in L2 descriptive writing. Asian-Pacific Journal of Second and Foreign Language Education, 1(1), 10. https://doi.org/10.1186/s40862-0160015-6

Troia, G. \& S. Graham (2002). The effectiveness of highly explicit, teacher-directed strategy instruction routine: Changing the writing performance of students with learning disabilities. Journal of Learning Disabilities 35, 290-305. https://doi.org/10.1177/00222194020350040101

van den Bergh, H., \& Rijlaarsdam, G. (2007). The dynamics of idea generation during writing: An online study. Studies in writing, 20, 125. https://doi.org/10.1108/S1572-6304(2007)0000020010

VanPatten, B. (1990). Attending to form and content in the input: An experiment in consciousness. Studies in second language acquisition, 12(3), 287-301. https://doi.org/10.1017/S0272263100009177

Zhang, C. (2013). Effect of instruction on ESL students' synthesis writing. Journal of second language writing, 22(1), 51-67. https://doi.org/10.1016/j.jslw.2012.12.001

\section{Appendix A}

\section{Interview Protocol}

1. How much time did you take to plan, approximately? 
2. Did you have enough time to plan before you started writing?

3. What do you think is the ideal amount of time to spend planning for this kind of task?

4. How did you spend the planning time before you started writing? In other words, what did you think about?

5. Can you walk me through the steps you went through when planning?

6. When we plan, it is possible to do multiple activities. Below, we have a list of possible activities. How much of your planning time did you spend on these activities?

\begin{tabular}{|l|l|}
\hline How much were you generating new ideas for the essay? & \\
\hline How much were you expanding on new ideas for the essay? & \\
\hline How much were you thinking about what information to use from the & \\
\hline Hources? & \\
\hline How much were you thinking of organizing the essay structure? & \\
\hline $\begin{array}{l}\text { How much were you reflecting on language: word choice, sentence } \\
\text { structure, grammar? }\end{array}$ & $100 \%$ \\
\hline
\end{tabular}

7. (Looking at notes together): I see you organized your notes in this manner, what thoughts guided you to make notes this way?

Now, we would like to ask you a little bit about the actual writing process

8. How often did you refer to your notes while you were writing? Why?

9. How did you use your time while you were writing? Assign a percentage for each activity (make sure it adds up to $100 \%$ ). 


\begin{tabular}{|l|l|}
\hline How much were you generating new ideas for the essay? & \\
\hline How much were you expanding on new ideas for the essay? & \\
\hline How much were you thinking about what information to use from the & \\
\hline How much were you thinking of organizing the ideas? & \\
\hline How much were you thinking of organizing the essay structure? & \\
\hline How much were you reflecting on language: word choice, sentence \\
structure, grammar?
\end{tabular}




\section{Appendix B}

CAEL Assessment Reporting Scale for Writing Performance

\begin{tabular}{|l|l|}
\hline Band Score & Description \\
\hline $80-90$ & Writes with authority and style demonstrating mastery of \\
appropriate, concise and persuasive academic writing.
\end{tabular}

https://www.cael.ca/wp-content/uploads/2017/06/CAEL-Reporting-Scale.pdf 